\title{
Theatrical performance as a public pedagogy of solidarity for intercultural learning
}

\author{
Lou Harvey* - University of Leeds, UK \\ Brad McCormick, Katy Vanden, Ree Collins and Patricia Suarez - Cap-a-Pie \\ and associates, UK
}

\begin{abstract}
This article is a post-hoc reflective theorization of a public engagement event based on research into UK-based international students' experiences of learning English. The event was a work-in-progress theatrical performance called The Translator, devised and produced by theatre company Cap-a-Pie and associates, and staged on two nights in June 2017 in Leeds. Our aim was to create an active learning experience for the public about how they relate to 'otherness' and difference in communication, and how they think about their own responses to difficult communicative situations. Lou first outlines her understanding of intercultural learning (Harvey, 2016, following Bakhtin, 1981), her engagement with Gert Biesta's pedagogy in the interest of publicness, and Biesta's own dialogue with Hannah Arendt on freedom and plurality. We then present filmed rehearsal footage and a written description of some of the scenes from The Translator. This is followed by audience responses, which demonstrate the audience's discomfort arising from different aspects of misunderstanding in the performance and how this prompted them to consider their own 'otherness' and their responsibilities for successful communication. The subsequent discussion draws on Lou's recent thinking in critical human rights theory to demonstrate how The Translator functioned as a public pedagogy of solidarity, in which the audience reflected on our mutual responsibility to work to understand each other regardless of our cultural backgrounds and the languages we speak.
\end{abstract}

Keywords: intercultural learning; performance; public pedagogy; public engagement

\section{Key messages}

- Theatrical performance can function as a public pedagogy of solidarity by giving the audience an affective, embodied experience through which they relate their own experience to that of the characters on stage.

- The basis of solidarity is not common social, cultural or political identity but a shared human desire and ability to make meaning, and a shared anxiety around being misunderstood.

- The shared inability to understand and make meaning in the performance generated learning for the audience, giving them a feeling of being 'othered', which led them to relate to the position of the cultural 'other' and to consider their own roles and responsibilities in communication. 


\section{Introduction}

This article is a post-hoc reflective theorization of a public engagement project, a work-in-progress theatrical performance called The Translator. The performance was supported using public funding by the National Lottery through Arts Council England, by the University of Leeds, and match-funding by the Society for Research into Higher Education. It has also created a slightly complex context of authorship. The project overall was co-produced between academic Lou Harvey and Cap-a-Pie theatre company, Brad McCormick (Artistic Director) and Katy Vanden (Producer). The performance was made by Cap-a-Pie and actors Ree Collins and Patricia Suarez, whose involvement ran for the duration of the project. In addition, we worked with a number of associate artists at different stages of the making process, who are credited below, and in the video featuring scenes from the rehearsal period (see www.youtube. $\mathrm{com} /$ watch?v=XIf6SR4juEw). Given that this article is an academic theorization of the performance, it is written in Lou's voice, where I/me/my refer to Lou, and we/us/our refer to all the named authors.

The performance was based on my research into UK-based international students' experiences of learning English and communicating interculturally. It was devised and produced by theatre company Cap-a-Pie and their associates, and staged on two nights in June 2017 in Leeds. With the performance, we aimed to create an active learning experience about how we relate to 'otherness' and difference in communication, and how we think about our own responses to difficult communicative situations. In this article, we consider how we met this objective, first of all by outlining the research on which the performance was based, my reasons for adapting it for performance, my approach to language and intercultural learning in both the original research and the public engagement project, and the understandings of 'public' and 'pedagogy' on which I draw. We then present a video of rehearsal footage from the performance and a verbal description of one of the scenes, and some of the audience responses from written evaluations and post-show discussions. I conclude by demonstrating how these responses, when read through the lenses of my approaches to intercultural learning and public pedagogy, make a case for understanding the performance as a public pedagogy of solidarity.

\section{Research and reasons for adaptation}

The research on which The Translator was based was an analysis of six UK-based international students' motivation for learning English. The following analytical vignette illustrates the experience of one of the participants, Eli:

Eli was a very enthusiastic and successful English learner in Iran, and considered herself fairly confident and proficient in English when she moved to the UK (to attend a private language school in advance of applying for a place at university). However, she found that although she had found speaking very easy and enjoyable in Iran, it became a source of anxiety, and she lost her confidence: although she was able to ask for things, she worried that she would not understand the response, and she felt like a young child, unable to speak properly and be taken seriously. She felt like the social class she had inhabited in Iran was now no longer recognized: whereas in Iran she had been 'somebody', she was now 'nobody', unable to tell people who she was and be recognized by them. This feeling motivated Eli to practise listening and speaking as much as 
possible, and she took small steps, feeling proud of herself for doing small things such as greeting her neighbours. Eli's desire to speak and be understood therefore motivated her to speak more, and also enabled her to accept that sometimes she would be misunderstood, because she was new to the language. As she gained more confidence in speaking English, she found opportunities for self-fulfilment that had not been available to her in Iran, and opportunities to help other Iranians to engage with life in the UK. Eventually Eli became comfortable enough in English to understand herself as 'an Iranian speaker of English', in which she could live in, with and through her Iranian/Persian-speaking identity and her British/English-speaking identity.

Like Eli, the other five participants all spoke good English when they came to the UK, but although they knew the forms of the language, they still found it very difficult to communicate, to use their voices and to feel understood. This was very destabilizing for them, even as so-called 'good' English speakers. This difficulty and destabilization is fundamental to why I wanted to adapt the research for performance: I wanted to use the dramatic medium to convey the 'drama' of this encounter, to communicate the anxiety and the sense of loss when one is unable to understand and be understood - even, and perhaps especially, when one is already proficient in the language and expects to be able to understand. This was the central purpose of the public engagement project: to create an active learning experience where the audience would understand this through feeling it themselves. My hope was that this would stimulate reflection in the audience on our responsibilities in communication at the personal level - to be conscious of, acknowledge, accommodate and negotiate meaning through different languages and communicative practices - and also at the public level - to understand that, contrary to popular media and government discourse, the onus for social participation and inclusion lies not only on the migrant but is a collective responsibility (see Harvey, 2018 for further discussion).

This article analyses the ways in which the audience's learning took place, and the ways in which the performance operated as a public intercultural pedagogy. At the heart of this analysis, therefore, are my approaches to intercultural learning and public pedagogy.

\section{Intercultural learning}

To theorize the participants' processes of, and motivation for, language and intercultural learning, I adopted a framework based on the work of Russian philosopher of language Mikhail Bakhtin (1981). Bakhtin's understanding of language is dialogic: our utterances (which may be linguistic, but also gestures, looks, silences and so on) are always in dialogue with other utterances, as they always respond to something that has been said before, and always anticipate a reply. Within Bakhtin's understanding, our utterances have material force - they make the world - and so a dialogic view of language is fundamentally about how the world is made in the relationship between the selves and the others engaged in the dialogue. Selves are in constant flux, with no fixed boundaries: individuals emerge in interaction with the social environment, through constantly making meaning with others. Thus, there is no absolute distinction between individual selves and others: rather, individuals are always related and co-dependent, with relationships being constantly worked out through their communicative utterances. We can never have a complete view of ourselves alone, and are dependent on others for self-understanding - the I cannot exist without the other: 
... one cannot even really see one's own exterior and comprehend it as a whole ... our real exterior can be seen and understood only by other people, because they are located outside us in space. (Bakhtin, 1986: 7)

To be means to be for another, and through the other, for oneself. A person has no internal sovereign territory, he [sic] is always and wholly on the boundary; looking inside himself, he looks into the eyes of another or with the eyes of another. ... I cannot manage without another, I cannot become myself without another; I must find myself in another by finding another in myself (in mutual reflection and mutual acceptance). (Bakhtin, 1984: 287)

We can only see and understand ourselves through what is reflected back to us by others: we account for 'the value of our own outward appearance from the standpoint of the possible impression it may produce on the other' (Bakhtin, 1990: 15). However, this is not to say that the relationship between the self and the other should be entirely indistinct. In order to have meaningful dialogue, some distinctiveness between individuals must be maintained. One's own perspective is vital when learning to understand another culture: one should not simply take on the perspective of the other, but also maintain one's unique self, by both entering and remaining outside. Bakhtin (1986: 6-7) calls this outsideness, and it is essential in order to be able to speak to and understand others:

Of course, a certain entry as a living being into a foreign culture, the possibility of seeing the world through its eyes, is a necessary part of the process of understanding it; but if this were the only aspect of the understanding, it would merely be duplication and would not entail anything new or enriching. Creative understanding does not renounce itself, its own place in time, its own culture; and it forgets nothing. In order to understand, it is immensely important for the person who understands to be located outside the object of his or her creative understanding - in time, in space, in culture.

For Bakhtin, then, intercultural understanding involves simultaneously entering and remaining outside the other culture. If outsideness is maintained, each participant and their perspectives are broadened, for 'each retains its own unity and open totality, but they are mutually enriched' (ibid.: 7). In other words, intercultural learning takes place. This mutual enrichment occurred for the six research participants, who learnt how to communicate in their new UK context through their developing English voices, which expressed their unique cultural identities and their own inflections of English. Eli, for example, developed a voice as an Iranian speaker of English, and learnt to live as both an Iranian person/Persian speaker and a British person/English speaker (Harvey, 2014; see also Harvey, 2015, 2016, 2017).

\section{Public pedagogy}

The research field of public pedagogy is an emerging one, with varied and contested definitions of public and pedagogy (see Sandlin et al., 2010; Burdick et al., 2014; Sandlin et al., 2017). My understanding of public pedagogy in this article follows the thinking of educationalist Gert Biesta, which I have found useful because of its conceptual parallels with Bakhtin's philosophy of language. 
Biesta (2014: 19) draws on the philosophy of Hannah Arendt to conceptualize the public realm as 'the space where freedom can appear'. The public realm is where human beings can act, in the sense of beginning an action, and where these beginnings are responded to and taken up by others - in this moment, one comes into the world and is free (following Arendt, 1958). However, one can never predict how others will respond to our beginnings - the impossibility of maintaining control of what we do is precisely the condition in which our beginnings can be recognized, and thereby enter the world (Arendt, 1958: 244). The key point for my argument is therefore that action is impossible without others, for 'to be isolated is to be deprived of the capacity to act' (ibid.: 188). This in turn, as Biesta (2014: 19) points out, means that the capacity to act is dependent on plurality, which he describes as 'the situation in which difference is not reduced to sameness' - or, as Arendt (1958: 8) puts it, plurality 'is the condition of human action'. Our freedom is therefore inextricable from the freedom of others. The public domain in which this freedom can appear is therefore not a space, but a quality of interaction (Biesta, 2014: 20): the polis is 'the organisation of the people as it arises out of acting and speaking together, and its true space lies between people living together for this purpose ... It is the space of appearance in the widest sense of the word' (Arendt, 1958: 198-9). In this sense, the public realm can be understood as a particular 'quality of human togetherness ... in which action is possible and freedom can appear' (Biesta, 2014: 21, 23).

Biesta $(2012,2014)$ goes on to posit three understandings of public pedagogy: pedagogy for the public, pedagogy of the public, and pedagogy in the interest of publicness. Pedagogy for the public is aimed at instructing the citizenry and relates most closely to traditional understandings of public engagement as transmission carried out by the didactic public intellectual, 'a solitary figure in a seat of epistemic power' (Sandlin et al., 2010: xxv). Pedagogy of the public is done by the public itself, rather than by external instructors, and relates most closely to collective learning and critical consciousness-raising, as espoused by critical educators such as Paulo Freire (2017; Freire et al., 2016) and Henry Giroux (for example, 2010; see also Savage, 2010). According to Biesta (2014: 22), both of these understandings of public pedagogy work towards the reduction of plurality: in the first case, by assuming an authoritative stance of telling the citizenry how to behave, and in the second case, by creating a specific 'regime of learning', which acts for change towards a particular concept of democracy rather than one that is 'radically open towards the future'. A pedagogy in the interest of publicness, in contrast, is one of 'an enactment of a concern for "publicness" - that is, a concern for the public quality of human togetherness and thus for the possibility of actors and events to become public' (ibid.: 23, original italics). It works towards, rather than against, the conditions under which, in Arendt's formulation, action is enabled and freedom can appear - a condition of plurality based on 'a citizenship of strangers' (Biesta, 2012: 684).

For Biesta, the notion of a 'citizenship of strangers' is fundamental to understanding the possibilities of plurality. Biesta (2014: 20-1) illustrates that Arendt's plurality is a rejection of the communitarian political notion that common action must be based on an underlying agreement and commonality. At stake in the preservation of plurality is understanding, 'an unending activity by which, in constant change and variation, we come to terms with, reconcile ourselves to reality, that is, try to be at home in the world' (Arendt, 1994: 307-8). Understanding in this sense relies not on a common identity but on the recognition of difference and strangeness - and it is this recognition on which common action depends. A 'citizenship of strangers' therefore 
constitutes a 'mode of human togetherness which is not after a common ground but rather articulates an interest in a common world' (Biesta, 2012: 690).

This relationality and ethics of plurality is also fundamental to the understanding of pedagogy I wish to present. Following Gaztambide-Fernández and Matute (2014: 56), I understand pedagogy as a relational, intentional process through which individuals enter into a relationship 'through which one makes an attempt to influence or "push against" the experiences of another'. As it is relational and intentional, the pedagogical encounter is always moved by an ethical imperative, as the question inheres of whose intentions are enacted on whom, and to what end. At the heart of this question is the relationship between the self and the other, which is fundamental to Biesta's 'citizenship of strangers' and the rejection of a common ground in favour of the articulation of interest in a common world. I have found Sara Ahmed's (2000) 'stranger' ethics useful for understanding how this citizenship might be enacted between individuals. Ahmed (ibid.) suggests that, rather than thinking of the other as a stranger to oneself, it is more productive to think of oneself and the other as strangers to each other, who both learn and develop through their mutual encounter. There are clear parallels here with Bakhtin's outsideness, and the movement on the boundary that creative understanding entails. A pedagogical encounter in which self and other meet each other as strangers - where both inhabit the boundary and learn with/from each other - may offer an enactment of Arendt's and Biesta's public realm, in which we are all 'others' to each other and where learning is part of the project of creating and sharing a common world.

In the following sections, I will present the performance itself and the audience's responses to it. I will draw upon my Bakhtinian conceptualization of intercultural learning to analyse how The Translator created a 'strange' encounter for the audience, how this encounter operated as a pedagogy, and how this pedagogy promotes and enacts the plurality of the public realm, as understood by Arendt and Biesta. Woven together, these different strands of thought will enable me to theorize The Translator as a public intercultural pedagogy of solidarity.

\section{The performance}

The Translator was a work-in-progress show of entirely devised material, working with the data and the themes from both my PhD research (Harvey, 2014) and a co-produced research project between myself and Cap-a-Pie in which we piloted Cap-a-Pie's Dramatic Enquiry technique as a method for understanding and enhancing university students' intercultural learning (Harvey et al., 2017). It developed from a previous shorter performance we had made in June 2015, Up and Up and Up Towards, which was performed at several public events at the University of Leeds. Our foundation for the form of this performance was the experience of my research participants: the assumption that you know what is going on around you, and then you realize that actually you do not understand as you thought you did, and there are unspoken rules of which you are not aware. Brad from Cap-a-Pie suggested that we could use this idea to apply to the theatre too, and that by playing with the audience's expectations around being at the theatre, we could put them in the position of discomfort that my participants had felt. This gave us a foundation for our form (see Harvey, 2018).

To devise content, we engaged in creative enquiry, a specific method developed by Cap-a-Pie that mixes creative activities with the Philosophy for Children programme. This involves starting with a stimulus, which for us was two pieces of verbatim text from my participants' stories, then brainstorming themes from those texts. From these 
activities, we developed characters with life histories, scenarios and dialogues. We then created a philosophical question, which was an open question involving two of the themes we had brainstormed from the data. Our question was 'What ambitions are acceptable?' This question led us to the story of Icarus, which became fundamental to Up and Up and Up Towards (see Harvey, forthcoming 2019) and also became woven into The Translator (see video at the link in the Introduction). To devise The Translator over two weeks in May and June 2017, we extended the creative enquiry to our two actors, Ree and Patricia, and broadened it by incorporating their own stories and experiences of not understanding. And now, because we were working with actors and objects, we were able to extend the enquiry beyond the written and spoken, and into performance and material domains. We were able to ask oblique as well as direct questions: not only what happened? but also put that into a story, make it a character, show it with an object. It expanded in scope so that responsibility emerged as a core theme alongside mis/understanding, and as part of the performance we asked the audience to think about their own language practices - how they listened, how they accommodated, how considerate they were, the extent to which they took responsibility for the communication being successful - as the description of the performance and responses below will demonstrate.

The Translator was shown on two evenings in June 2017 at the Holbeck Underground Ballroom (The HUB), a theatre in south Leeds run by theatre company Slung Low. Over the two nights, the show was seen by an audience of 109. Some of these I had personally invited specifically for their professional affiliations, such as practitioners in language and intercultural education (university student support, educational engagement and widening participation, school language teachers) and practitioners working in demanding communicative contexts (migrant support, social and youth work, advocacy work). Others attended as members of the general public, including immigrants to the UK (local recent arrivals, international students) and local people from settled communities, mostly Slung Low's local Holbeck audience in response to their mailing list. Ticketing was run on a pay what you decide basis.

The two performances were a little different in content, as we had a lot of material we wanted to show, and we did further work on the scenes between the two performances. It was performed by Ree and Patricia, and premised upon them playing a series of games with each other as part of an overarching game with the audience. It also involved varying degrees of audience participation in some of the games. The video at the link in the Introduction to this article presents rehearsal footage of three of the scenes, so we are unable to show any audience participation - owing to the practicalities of effectively capturing theatre on film, it was felt that filming in the rehearsal room would be more appropriate at this stage of the process. I then verbally describe the 'linguistic bullying' scene, which was one of the most participatory. I have chosen this scene because it can be described more easily than some other scenes outside the context of the whole performance, and it elicited some of the most explicit responses in the written evaluations and post-show discussions. 
Figure 1: Still and title card from The Translator, a video of rehearsal scenes

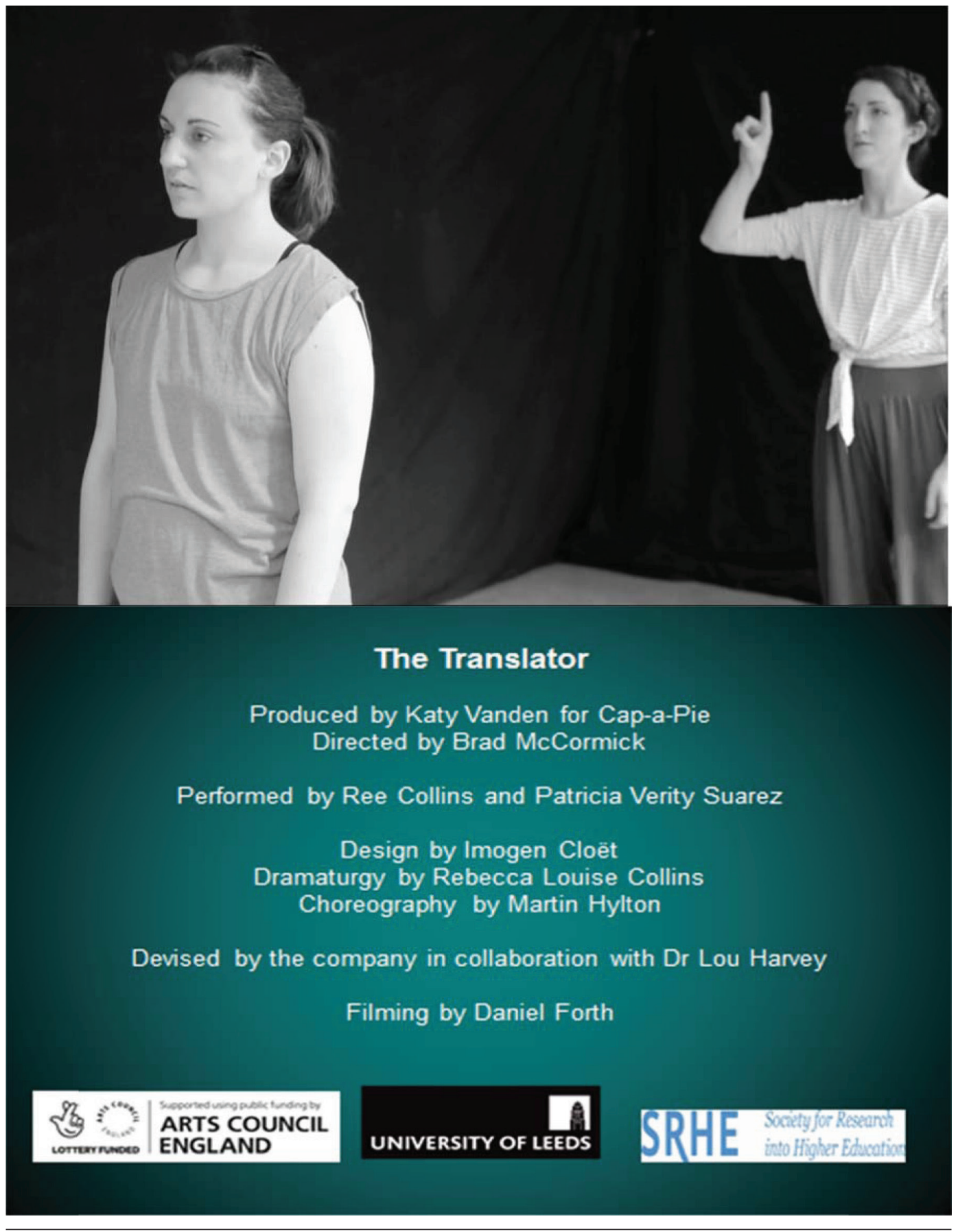

\section{Linguistic bullying}

The actors are sitting opposite each other at a small table with a phone. They announce cheerfully to the audience, 'We're in a doctor's office!' Ree turns to the audience and says, conspiratorially and with relish, 'She might be dying'. They then perform the following dialogue, with Ree speaking assertively as the more powerful or higherstatus participant, and Patricia speaking more meekly as the lower-status participant: 
Patricia: I don't understand.

Ree: Were you listening?

Patricia: Yes.

Ree: I don't think you were.

Patricia: Could you tell me again?

Ree: I don't have the time.

Patricia: I need this to happen.

Ree: It's not my problem.

They pause and perform the dialogue again and then a third time. They pause, then jump up and move the chairs around. From their new positions, they announce cheerfully, 'We're on a bus! Round 1!' They perform the dialogue again with Ree as the bus driver and Patricia as the passenger, again with Ree as the higher-status participant, but this time they are more equal. After the dialogue they turn to the audience and ask them to join the scene. Patricia, gleefully and coquettishly, tells the audience, 'Your objective is to make me feel like shit.' The actors invite the audience to tut (clicking the tongue against the back of the front teeth to express annoyance) loudly when Patricia gets on the bus because she's making them late. They ask a section of the audience to practise tutting and are very encouraging to the audience, responding with lavish praise. They ask another section of the audience to practise sighing frustratedly, again responding with great encouragement. They ask the audience to incorporate some eye-rolling and head-shaking. They perform the dialogue again, this time with the audience tutting and sighing at Patricia, and then they congratulate the audience on their performance, Patricia saying playfully, 'Wow, I really felt like shit!' The actors then ask the audience to shout, 'Come on!' and 'Oh hell, I'm gonna be late!' Patricia turns to one audience member at the front and flirtatiously says, 'I've got a special task for you ... it's a bit naughty ... can you tell me to fuck off?' The audience member shouts 'fuck off', and they practise a couple of times. Patricia reminds the audience that they need to make her feel like shit because she is making the bus late and they might be late for work, the driver might lose her job, they might lose their jobs and be unable to pay their rent, their banking deal might fall through, causing a loss of billions to the economy, and cancer will not be cured because they were too late to add the enzyme. The economy is going to collapse and people will die because the bus is late. The actors perform the dialogue again, with the audience shouting at Patricia.

The actors change their positions again and cheerfully announce, 'We're in a shop!' The actors perform the dialogue again, with the audience shouting at Patricia as they were during the bus scene. Ree congratulates the audience on their performance and suggests they can take it up a step. She moves into the audience while Patricia stands with her back to them. Ree hands a piece of paper to one of the audience and asks them to say the words; the audience member refuses. Ree hands the paper to the next person, who shouts, 'You stupid bitch!' The audience burst into laughter. He then shouts, 'Fucking go home, for fuck's sake!' Ree congratulates him on his performance and asks him to do the scene. Patricia says, 'I don't understand', and the audience member shouts at her while she recites the dialogue, with a nervous giggle in his voice. The audience are laughing and Ree encourages them to join in the chant, which some, but not all, do. The laughter gradually stops while the audience are shouting, initially with gusto, but gradually less enthusiastically. Ree comes back to the stage and announces that they can take it up another level, as the audience have earnt it. They move back to the table; Patricia stands, Ree sits. They cheerfully announce, 'We're 
in a deportation centre! Final round!' Patricia says, 'I don't understand'. Lights fade to black.

\section{Audience responses to the performance}

Much of the post-show discussion and the written comments were explicitly or implicitly about the audience's discomfort about various aspects of the performance. This discomfort arose from different aspects of mis/understanding. At times, the audience did not understand what was going on in the performance, or how to respond to it:

We had a conversation here about trying to establish the rules about how you're supposed to react - so when was it OK to laugh - or laughing at one point and then realizing am I supposed to laugh at this point?

There was one point I was laughing silently because everyone else wasn't laughing [laughter] ... I shouldn't be laughing, this isn't funny any more this isn't meant to be funny any more and I can't laugh out loud any more because that's the wrong thing to do - genuinely I felt that I'd have to laugh to myself.

... and there was a point [where] I was looking for a cue from the performers as to how we should react - and she wasn't giving any cues that l'd recognize - so I wasn't sure how to react.

One audience member talked about being in the position of being unable to understand, and the feeling of being 'othered' that resulted:

I suppose it's quite a perverse thing to say but it was interesting to be in that position, of feeling like I was in that position - like I say, it's not a nice thing, but it's an interesting position to be in nonetheless - and it gives you a better understanding, the closest you could probably get, to what it must feel like in the actual situation.

The audience also felt uncomfortable at their own role or complicity in the actors' misunderstanding, or in making the actors feel bad about their misunderstanding:

I actually felt uncomfortable because after a while I realized this is like that experiment where people electrocute each other, you know, [laughter] and I thought, how long do we ... she said this is making her feel really shit, I thought, OK, I didn't really want to - I mean, I know it's supposed to be the play but actually I thought, no, this is too mean [laughs] but, yeah, it does make me think.

I think what I struggled with on a personal level was - it was very compassionate, but to get there, there was all that aggression, and maybe if they'd been asking me to - swear or - I think I'd have struggled with that level of anger and that almost that hatred - feeling awkward, I felt really, really awkward - even though it was just a performance - just even pretending [laughs] to do that to another person made me feel uncomfortable.

For some audience members, their discomfort led them to reflect on what understanding means, and how it is not necessarily connected with speaking the same language, or even with language at all: 
It did make me feel extremely uncomfortable - but in a sort of good way - and I think the thing I feel most uncomfortable about it that there's that simplicity about using language as in non-English and English language, but actually I think what it did is a really good reflection of our indigenous communities and the perceived or actual divisions within our communities and societies as they are, so it's simple to use English and non-English but actually I think it reflects something much wider than that ... you know everybody can feel alienated, whether you've got English language or not.

There are so many other cultural aspects - for instance, in the Netherlands you're supposed to be very direct with people - meanwhile in the UK, if you're the same, it's perceived as rude - and this can affect your professional and your personal life.

My husband, he's a bit on the autistic spectrum, so we're having a conversation and he's always saying to me, 'I don't understand' and I just get like, 'Let me finish my sentence and you will!' - but I'm going to take it slower [laughter].

The performance also prompted reflection from audience members who had experienced overt hostility at being unable to understand:

You are describing as the viewer, but we are non-natives, so we have been on the other side - we've been the ones that have been laughed at ... and we're both proficient speakers, but still I've felt like an idiot publicly and it's really stressful and you really feel like ... I've never thought about it in this way - Icarus? I've never thought about it in those terms but - you have to be a very strong-minded and very resilient person to overcome those difficulties because for us international students it happens every single day - everywhere - so if you're not resilient enough, you cannot really move forward and you get to talk only with your friends because you don't want to be laughed at, so in a way it's like you sabotage yourself because you try to stay in a safe environment and so you make less progress and it's just a vicious circle - like self-preservation instinct.

I think, as a different perspective, I am here as an expat, so I could see the steps - it's not always that we are threatened about what can happen to us if we don't get understood - it's like it could be a night out and something happens - it could be when we go to the doctor - it's not always about us being thrown away out of the country, hopefully [laughter], Brexit doesn't help - but I mean it's the daily life, the daily struggle, everywhere in every situation - on the bus - that's the thing, this is what I like is that this is every moment of our social life.

A lot of the time, it's not just the blatant get out of the country or fuck off or anything like that, it's a lot of the smaller stuff which persists and permeates and are quite insistent, and they're the ones I think that can make just as big an impact.

Very often, actually, you can be understood with what you say even if you are not using the appropriate language - but you have very different people in front of you - sometimes people are making an effort to try to get what 
you want to say, and sometimes people make no effort to do this ... very often you are in these kind of situations, which are extremely painful.

This notion of 'making an effort', as expressed by this audience member, relates to the concept of responsibility for successful communication and understanding, reflections on which were evident in some of the reflective written responses:

Whose problem is when they don't understand me? Whose problem is when I don't understand them?

I can sometimes be brusque/curt when I am stressed. I saw myself in some ways in the bus sketch, and it made me question my own behaviour. Do we need to be annoyed in such overt/offensive ways?

I liked the audience participation bits. Made me reflect on my effect on others.

How must migrants feel in a new place and setting up home? How much effort do we put into understanding one another? How much into making ourselves understood? How aware are we of the impact of that?

It made me think about a couple of things from this last week - seeing UKBA [UK Border Agency] at work and a child tax credit form. About access and power. And hospitality - how are we/how am I hospitable?

Tolerance and patience - maybe I don't have enough of either.

Do I treat people with the respect and understanding they deserve when I'm not being understood by them? Do I expect them to work harder at understanding me than I expect myself to work at finding a way to communicate effectively?

\section{Making sense of the audience responses}

To make sense of these responses, I would like to return to my original motivation for adapting the research for performance. These audience responses reiterated for me why I had not wanted to do a verbatim piece of theatre about the research participants' stories, and led me to think about the role of feeling and emotion, specifically discomfort, in creating an active learning experience for the audience of The Translator. To develop my thoughts on this, I have drawn on critical human rights education, specifically Michalinos Zembylas's critique of Richard Rorty's concept of 'sentimental education'. For Rorty, sentimental education aims to cultivate an affective sympathy with the suffering of others, and thereby an identification with them; it is therefore 'aimed at modifying the way individuals feel by cultivating moral feelings' (Rorty, 1998: 181; Zembylas, 2016: 1,156, following Barreto, 2011). However, sad and sentimental stories are ubiquitous, given our culturally popular narrative orientation. Thinking about sentimental education in this way brought me to understand that my unwillingness to do a verbatim adaptation was based on my belief that 'cultivating affective sympathy', although it may move people to make a gesture of support (giving money or supplies to refugee causes, for example), does not necessarily change the way that people see the world or their own roles in it, nor motivate them to change their own behaviour. Not everyone has had the experience of living in a different place and in a different language, and certainly not everyone has had some of the desperate and traumatic experiences that can accompany that. So, given these differences, often 
gulfs, in our experience, how can we connect with others, and what kind of education might we aim for with the aim of making this connection? How can we cultivate 'sympathy with the other's suffering' (Zembylas, 2016: 1165)?

My understandings of this chime with moves in critical human rights education towards seeking 'a pedagogical orientation that avoids ... a "cheap sentimental" approach (i.e. the reading of sad and sentimental stories of horrendous suffering which move us to pity, patting ourselves on the back, and then resuming our ordinary life)' (ibid.: 1152). Zembylas (2016) critiques 'cheap sentimentality' and Rorty's concept of sentimentality (see also Zembylas, 2013), but emotion does play an important role in learning: to paraphrase Zembylas, the aim of education (whether intercultural or human rights education) is towards moving away from sets of universal principles towards a critical enquiry of inequalities and abuses 'in a way that touches learners affectively yet not superficially' (Zembylas: 1155, my emphasis). This affective, emotional dimension can be seen to be at work in the audience responses, in the strong feelings of discomfort and strangeness they express. And given that this emotional response arose from the inability to understand, and from reflections on mis/understanding, I suggest it was based on a shared desire to communicate and to understand, to make sense of our experience. The experience of trying to make meaning and of being misunderstood is one that we all share, regardless of the language we speak - as one audience member pointed out, 'everybody can feel alienated, whether you've got English language or not'. Furthermore, when we try to make meaning and make ourselves understood, we do so through our bodies, through our speech and our gesture, as the material performance of being in the world. The experience of having a body, and of making meaning through our bodies, is another experience that we all share. And it was in their bodies, in their embodied feelings of discomfort, that the audience responded to misunderstanding, whether their own or that of the actors. I suggest that this emotional and physical response of discomfort was fundamental to learning about otherness in The Translator (see Frimberger, 2016, 2017; Frimberger et al., 2018, on affect and aesthetics in intercultural learning).

To explicate this as a learning experience, I return to the Bakhtinian perspective on intercultural learning from my original research, which I introduced at the beginning of this article. Bakhtin claimed that although each participant must 'find the other in themselves', they must also maintain their unique sense of self and remain different from each other. For Bakhtin (1986: 7), this outsideness is fundamental to intercultural growth, or to reach creative understanding, in which each participant 'retains its own unity and open totality, but they are mutually enriched'. I suggest that the audience responses and questions are indicative of a move towards creative understanding - they were enriched through finding the other in themselves, through the discomfort of engaging with misunderstanding. For some, this was the discomfort of feeling 'othered' as a result of being unable to understand themselves; for some, it was through the discomfort of identifying their own experiences of misunderstanding in the performance; for some, it was through the discomfort of engendering and being complicit in someone else's suffering as a result of their misunderstanding. This discomfort offered them a glimpse of themselves from outside themselves, as indicated in their reflections on their behaviour, their effect on others, and their responsibilities in communication. This shared experience of discomfort, based on misunderstanding and the inability to make meaning, forms the basis of my understanding of The Translator as a pedagogy of solidarity. 


\section{A public (intercultural) pedagogy of solidarity}

As Rubén Gaztambide-Fernández (2012: 46) points out, solidarity is a much-used but little-theorized concept, generally referring to 'particular types of social relations between individuals as well as groups' and hinging on 'similarities in characteristics, political interests, social needs, or moral obligations'. Solidarity as it is commonly used is based on group identities, or communitarian politics, and would therefore be rejected by Arendt (1994) for not adequately accounting for the plurality on which common action depends. Solidarity in this sense is therefore unsatisfactory for my project, as it will always exclude certain groups, relating to some and not to others. Instead, Gaztambide-Fernández (2012: 46) calls for a more radical and theoretically complex conception of solidarity that 'insists on relationships of incommensurable interdependency'. The active learning experience The Translatorgenerated, understood as a Bakhtinian process of moving towards creative understanding, can provide such a conception of solidarity. In generating a learning experience based on discomfort arising from thwarting the ability to make meaning, The Translator drew attention to precisely this desire and ability to make meaning, and the discomfort arising from its obstruction, as shared human experience. This shared human experience is one of both relationality, drawing attention to our similarities, and one of incommensurability, highlighting our insurmountable differences, our always-otherness to each other in which we strive to make ourselves intelligible. A solidarity based on communitarian politics always necessarily draws a boundary of inclusion/exclusion; in contrast, solidarity based on our desire and in/ability to make meaning asks us to live our lives on that boundary, recognizing our 'relationships of incommensurable interdependency'. This incommensurable interdependency was also inherent in the pedagogical aspects of the performance, where the performance makers and I, as the pedagogues, were able to 'push against' the audience's experiences (Gaztambide-Fernández and Matute, 2014: 56), while also acknowledging the audience as irreconcilable others, not telling them our intended message, but instead inviting them to feel, with us, the discomfort of being unable to bridge our strangenesses. We did not seek to control the audience's experience in the service of a particular learning outcome, but rather offered what Rich and Sandlin (2017) call an 'interruptive enactment of human togetherness'. In this way, the performance functioned as a pedagogy in the interest of publicness (Biesta, 2014), which performed and enabled recognition of our difference and strangeness from each other, our responsibilities to each other, and the interdependency of our individual freedom as we all 'try to be at home in the world' (Arendt, 1994: 308).

\section{Conclusion}

The Translator can therefore be understood as a public pedagogy of solidarity, where the basis of solidarity is the desire and ability to make meaning, and the anxiety of being misunderstood. The feelings of discomfort from misunderstanding and being misunderstood generated learning and reflection for the audience, prompting them to consider their own 'otherness' in the feeling of being 'othered', and to consider their own roles and responsibilities in communication.

This project was based on my desire to create an active learning experience about how we relate to 'otherness', how we respond to difficult communicative situations, and how we take responsibility for our roles in communication and understanding. My desire to do this was to start to pose a challenge to prevalent government and media discourses in the UK about language and social cohesion, which continue unabated. 
(As I have been writing this article, former UK government official and 'integration tsar' Louise Casey (2018) has suggested on a prominent UK radio programme that the UK government should set a date by which 'everyone in the country can speak a common language'). Some of the audience responses to The Translator demonstrated their reflections on the role of language in understanding each other, specifically how understanding is not dependent on speaking the same language, and sometimes not even dependent on language at all (see, for example, Pennycook, 2018). This is not to suggest that new arrivals to the UK should not learn English, as to do so opens invaluable opportunities for social participation (Simpson, forthcoming). Rather, it is part of my more radical call for a grass-roots challenge to oppressive monolingual ideologies that do not account for the variety and multiplicity of people's communicative abilities and experience. It is a call for understanding people not in terms of difference or similarity on the basis of language (or ethnicity, gender, race, age, ability, religion, or any other identity category), but rather as similar in our incommensurable difference from each other, which is the only thing we all really share. It is a call for more relational ways of understanding the world, by decentring ourselves and recognizing our own strangeness to others. It is a call for interruption (following Biesta, 2014), for encounters that make it more difficult for us to think, feel and act in our accustomed ways (see Zembylas and McGlynn, 2012: 53). This, of course, poses another major challenge in our neo-liberal times: articulating the value of such pedagogical interruptions, of making manifest what Zembylas (2016: 1163) calls the 'individual everyday acts' that contribute to gradual political change, in ways that speak to funders and make the continuance of such work possible, while also expanding the narrow concepts of evaluation, measurement and capture so prevalent in public engagement and impact discourses. Addressing this challenge would itself constitute an interruption to neoliberal discourse, with a belief that things can be done differently (Biesta, 2014: 23) which is, after all, a belief fundamental to engaged research.

A luta continua!

\section{Acknowledgements}

This has been a long-standing and at times slightly unwieldy project, involving a number of funders and supporters. Our heartfelt thanks go to these funders for making the project possible: Arts Council England, who funded us through the Grants for the Arts Programme supported using public funding by the National Lottery; the Cultural Institute at the University of Leeds; the Public Engagement Team at the University of Leeds; and the Society for Research into Higher Education (SRHE), whose Prize for Newer Researchers, awarded to Lou in 2016, enabled us to offer essential match funding. Many associates and colleagues have offered us valuable expertise and support: perhaps first and foremost is Slung Low, who hosted Cap-a-Pie for a residency week in June 2017, offered rehearsal, performance, living and socializing space at The $H \cup B$, and put in all the work necessary to host us, promote us, and ensure that all went smoothly on the nights. Heartfelt thanks go to the Public Engagement Fellowship scheme at the University of Leeds, in particular Alexa Ruppertsberg, Sue Pavitt and the 2016/17 Public Engagement Fellows, whose practical and emotional support enabled this project to come to fruition, and to go on to win the University of Leeds Public Engagement Award for Dissemination of Research in September 2017, of which we are immensely proud. Thanks also to the Leeds Creative Labs scheme, who brought Lou and Cap-a-Pie together in the first place; thanks again to SRHE and the Cultural Institute for their enthusiasm for, and promotion of, the project, and to all the friends 
and colleagues whose unwavering support has given us the energy to persist when barriers loomed - especially my partners-in-art at the School of Education, Jessica Bradley and James Simpson - diolch o galon.

\section{Notes on the contributors}

Lou Harvey is Lecturer in Language Education at the University of Leeds, specializing in language and intercultural learning, with particular interests in the relationship between voice and learning in publicly engaged and arts-based research.

Brad McCormick and Katy Vanden are, respectively, Artistic Director and Producer of Cap-a-Pie theatre company (www.cap-a-pie.co.uk), and Ree Collins and Patricia

Suarez are actor associates who joined the company on this project.

\section{References}

Ahmed, S. (2000) Strange Encounters: Embodied others in post-coloniality. London: Routledge.

Arendt, H. (1958) The Human Condition. Chicago: University of Chicago Press.

Arendt, H. (1994) 'Understanding and politics (the difficulties of understanding)'. In Arendt, H. Essays in Understanding, 1930-1954. Ed. Kohn, J. New York: Harcourt, Brace and Co., 307-27.

Bakhtin, M.M. (1981) The Dialogic Imagination: Four essays. Ed. Holquist, M. Trans. Emerson, C. and Holquist, M. Austin: University of Texas Press.

Bakhtin, M. (1984) Problems of Dostoevsky's Poetics. Ed. and Trans. Emerson, C. Minneapolis: University of Minnesota Press.

Bakhtin, M.M. (1986) Speech Genres and Other Late Essays. Ed. Emerson, C. and Holquist, M. Trans. McGee, V.W. Austin: University of Texas Press.

Bakhtin, M.M. (1990) Art and Answerability: Early philosophical essays. Ed. Holquist, M. and Liapunov, V. Trans. Liapunov, V. Austin: University of Texas Press.

Barreto, J.-M. (2011) 'Rorty and human rights: Contingency, emotions and how to defend human rights telling stories'. Utrecht Law Review, 7 (2), 93-112.

Biesta, G. (2012) 'Becoming public: Public pedagogy, citizenship and the public sphere'. Social and Cultural Geography, 13 (7), 683-97.

Biesta, G. (2014) 'Making pedagogy public: For the public, of the public, or in the interest of publicness?'. In Burdick, J., Sandlin, J.A. and O'Malley, M.P. (eds) Problematizing Public Pedagogy. New York: Routledge, 15-25.

Burdick, J., Sandlin, J.A. and O'Malley, M.P. (eds) (2014) Problematizing Public Pedagogy. New York: Routledge.

Casey, L. (2018) Interview on Westminster Hour, BBC Radio 4 (11 March).

Freire, P. (2017) Pedagogy of the Oppressed. Trans. Ramos, M.B. London: Penguin.

Freire, P., Araújo Freire, A.M. and de Oliveira, W. (2016) Pedagogy of Solidarity. London: Routledge.

Frimberger, K. (2016) 'A Brechtian theatre pedagogy for intercultural education research'. Language and Intercultural Communication, 16 (2), 130-47.

Frimberger, K. (2017) 'The ethics of performative approaches in intercultural education'. In Crutchfield, J. and Schewe, M. (eds) Going Performative in Intercultural Education: International contexts, theoretical perspectives and models of practice. Bristol: Multilingual Matters, 21-40.

Frimberger, K., White, R. and Ma, L. (2018) '"If I didn't know you what would you want me to see?": Poetic mappings in neo-materialist research with young asylum seekers and refugees'. Applied Linguistics Review, 9 (2-3), 391-419.

Gaztambide-Fernández, R.A. (2012) 'Decolonization and the pedagogy of solidarity'. Decolonization: Indigeneity, Education and Society, 1 (1), 41-67.

Gaztambide-Fernández, R.A. and Arráiz Matute, A. (2014) '"Pushing against": Relationality, intentionality, and the ethical imperative of pedagogy'. In Burdick, J., Sandlin, J.A. and O'Malley, M.P. (eds) Problematizing Public Pedagogy. New York: Routledge, 52-64.

Giroux, H.A. (2010) 'Neoliberalism as public pedagogy'. In Sandlin, J.A., Schultz, B.D. and Burdick, J. (eds) Handbook of Public Pedagogy: Education and learning beyond schooling. New York: Routledge, 486-99.

Harvey, L. (2014) 'Language Learning Motivation as Ideological Becoming: Dialogues with six English-language learners'. Unpublished PhD thesis, University of Manchester. 
Harvey, L. (2015) 'Beyond member-checking: A dialogic approach to the research interview'. International Journal of Research and Method in Education, 38 (1), 23-38.

Harvey, L. (2016) '"I am Italian in the world": A mobile student's story of language learning and ideological becoming'. Language and Intercultural Communication, 16 (3), 368-83.

Harvey, L. (2017) 'Language learning motivation as ideological becoming'. System, 65, 69-77.

Harvey, L. (2018) 'Adapting intercultural research for performance: Enacting hospitality in interdisciplinary collaboration and public engagement'. Arts and Humanities in Higher Education, 17 (4), 371-87.

Harvey, L. (forthcoming 2019) 'Entangled trans-ing: Co-creating a performance of language and intercultural research'. In Moore, E., Bradley, J. and Simpson, J. (eds) Translanguaging as Transformation: The collaborative construction of new linguistic realities. Bristol: Multilingual Matters.

Harvey, L., McCormick, B. and Vanden, K. (2017) 'Learning on the boundary: Developing Dramatic Enquiry for intercultural education'. Paper presented at the Society for Research into Higher Education (SRHE) Annual Research Conference, Newport, Wales, 6-8 December 2017. Online. www.srhe.ac.uk/conference2017/abstracts/0037.pdf (accessed 5 November 2018).

Pennycook, A. (2018) Posthumanist Applied Linguistics. London: Routledge.

Rich, E. and Sandlin, J.A. (2017) 'Physical cultural studies and public pedagogies'. In Silk, M.L., Andrews, D.L. and Thorpe, H. (eds) Routledge Handbook of Physical Cultural Studies. London: Routledge, 549-57.

Rorty, R. (1998) 'Human rights, rationality, and sentimentality'. In Rorty, R. Truth and Progress (Philosophical Papers Vol. 3). Cambridge: Cambridge University Press, 167-85.

Sandlin, J.A., Burdick, J. and Rich, E. (2017) 'Problematizing public engagement within public pedagogy research and practice'. Discourse: Studies in the Cultural Politics of Education, 38 (6), 823-35.

Sandlin, J.A., Schultz, B.D. and Burdick, J. (eds) (2010) Handbook of Public Pedagogy: Education and learning beyond schooling. New York: Routledge.

Savage, G.C. (2010) 'Problematizing "public pedagogy" in educational research'. In Sandlin, J.A., Schultz, B.D. and Burdick, J. (eds) Handbook of Public Pedagogy: Education and learning beyond schooling. New York: Routledge, 103-15.

Simpson, J. (forthcoming) 'Policy and adult migrant language education in the UK'. In Cooke, M. and Peutrell, R. (eds) Brokering Britain, Educating Citizens. Bristol: Multilingual Matters.

Zembylas, M. (2013) 'The "crisis of pity" and the radicalization of solidarity: Toward critical pedagogies of compassion'. Educational Studies, 49 (6), 504-21.

Zembylas, M. (2016) 'Toward a critical-sentimental orientation in human rights education'. Educational Philosophy and Theory, 48 (11), 1151-67.

Zembylas, M. and McGlynn, C. (2012) 'Discomforting pedagogies: Emotional tensions, ethical dilemmas and transformative possibilities'. British Educational Research Journal, 38 (1), 41-59. 